\title{
COMPLEX PROGRAM OF DIAGNOSTICS AND TREATMENT OF POLYTRAUMATIZED PATIENTS WITH II-III DEGREES OBESITY
}

DOI: 10.36740/WLek202003122

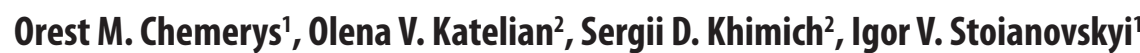 \\ 'DANYLO HALYTSKY LVIV NATIONAL MEDICAL UNIVERSITY, LVIV, UKRAINE \\ 2NATIONAL PIROGOV MEMORIAL MEDICAL UNIVERSITY, VINNYTSIA, UKRAINE
}

\begin{abstract}
The aim: Elaboration of the complex program of diagnostics and treatment of the polytraumatized overweight patients.

Materials and methods: Clinical material was composed of 64 patients with the combined body trauma who suffered from II-III grade obesity.

Results: Main principles of rendering the aid to the polytraumatized overweight patients included the pathophysiological and topographic features of the group. The obtained study results confirmed the credible difference of the traumatic disease progress in the patients with the normal weight and overweight patients which was the basis of our differential complex treatment program.

The treatment tactics also had certain characteristics connected with the obesity. The development of RDS syndrome is a typical stage of the traumatic disease during the blunt thoracal trauma in case of obesity. The programmed and urgent relaparotomy, as a method of the stage treatment in the present group of patients, is the integral component of the blunt abdominal injury in case of obesity.

Conclusions: The study results proved that our complex program of diagnostics and treatment of the polytraumatized patients shall be basic for the patients with II-III grade obesity.
\end{abstract}

KEY WORDS: polytrauma, obesity, diagnostics, treatment

Wiad Lek. 2020;73(3):521-524

\section{INTRODUCTION}

It is widely known that the issue of polytrauma is one of the most topical issues in surgery. The patients with the excess weight and different grades of obesity demand special approach among the multitude of the traumatized patients. Thus, as it was shown by some researchers, the overweight injured people suffer more in the course of traumatic disease as compared to the people with the normal weight $[1,2,3]$. Besides, the references provide only few publications as to the diagnostic characteristics and surgical treatment of the polytraumatized people against the obesity background, and there are practically no clear algorithms as to the diagnostic examination of such patients $[4,5]$.

The latter may be confirmed by the constant growth of the obesity rates, connected with the reduction of the physical activity of population [6]. Specific physiological processes of the obesity cause the most severe injuries, in particular, the skeleton injuries, and high risks of the development of frequently mortal complications. In case of the high BMI, such characteristics of organism play an important role at different stages of medical aid, which preconditions the necessity of specific technical surgical approaches and demand the special surgical nursing $[7,8]$.

The stated facts create the new challenges for the clinician, mainly, in the studying of the diagnostic value of clinical, instrumental, and special methods of examination, elaboration of the differential programs of the complex treatment of patients suffering from the obesity with regard to the characteristics of the traumatic disease and clarifying the impact of the differential complex treatment programs upon the dynamics of major vital indexes (parameters), functional and cosmetic components of the consequences of overweight patients surgical treatment in the format of perspective treatment technology $[9,10]$.

\section{THE AIM}

Elaboration of the complex program of diagnostics and treatment of the polytraumatized overweight patients.

\section{MATERIALS AND METHODS}

Clinical material was composed of 64 patients with the combined body trauma who suffered from II-III grade obesity. Depending upon the set tasks, the patients were subdivided into two clinical groups - major (34 patients) and approbation (30 patients). Main characteristics of the clinical groups are shown in Table I.

The study consisted of two stages. At stage I the components of the program of diagnostics and treatment of the overweight patients were defined for the patients of the major group, and at the stage II - the outlined principles were applied to the approbation group patients. 
Table I. Main characteristics of the clinical groups according to the BMI and sex

\begin{tabular}{ccccc} 
& BMI & Age & Men & Women \\
\hline Major group & $37.2 \pm 0.3$ & $56.6 \pm 1.4$ & $20(58.8 \%)$ & $14(41.2 \%)$ \\
\hline Approbation group & $37.4 \pm 0.3$ & $56.2 \pm 1.3$ & $17(56.7 \%)$ & $14(43.3 \%)$ \\
\hline
\end{tabular}

Table II. General characteristics of the closed chest injury

\begin{tabular}{|c|c|c|c|c|c|c|c|c|c|}
\hline & \multicolumn{3}{|c|}{ Ribs fracture } & \multicolumn{3}{|c|}{ Undrained } & \multicolumn{3}{|c|}{ Drained } \\
\hline & $\mathbf{n}$ & $\%$ & $\mathbf{p}$ & $\mathbf{n}$ & $\%$ & $\mathbf{p}$ & $\mathbf{n}$ & $\%$ & $\mathbf{p}$ \\
\hline Major group & 27 & 79.4 & \multirow{2}{*}{$\begin{array}{l}\leq 0.05 \\
X^{2}=4.34\end{array}$} & 11 & 32.4 & \multirow{2}{*}{$\begin{array}{c}>0.05 \\
x^{2}=0.04\end{array}$} & 16 & 47.1 & \multirow{2}{*}{$\begin{array}{c}>0.05 \\
x^{2}=2.49\end{array}$} \\
\hline Approbation group & 29 & 96.7 & & 9 & 30.0 & & 20 & 66.7 & \\
\hline
\end{tabular}

Table III. Invasive diagnostic methods in case of polytrauma against the obesity background

\begin{tabular}{|c|c|c|c|c|c|c|}
\hline \multirow[t]{2}{*}{ Clinical group } & \multicolumn{2}{|c|}{ Abdominal paracentesis } & \multirow{2}{*}{$\begin{array}{l}p / \\
X^{2}\end{array}$} & \multicolumn{2}{|c|}{$\begin{array}{c}\text { Diagnostic } \\
\text { videolaryngoscopy }\end{array}$} & \multirow{2}{*}{$\begin{array}{l}p / \\
x^{2}\end{array}$} \\
\hline & $\mathbf{n}$ & $\%$ & & $n$ & $\%$ & \\
\hline $\begin{array}{l}\text { Major } \\
(n=34)\end{array}$ & 29 & 85.0 & - & 6 & 17.7 & - \\
\hline $\begin{array}{l}\text { Approbation } \\
(n=30)\end{array}$ & 30 & 100.0 & $\begin{array}{c}\leq 0.05 / \\
4.79\end{array}$ & 5 & 16.7 & $\begin{array}{c}>0.05 / \\
0.01\end{array}$ \\
\hline
\end{tabular}

Within the diagnostics the following methods were applied: general clinical, laboratory and biochemical, instrumental (ultrasonography, craniography, x-radiography of thoracic organs, pelvis, extremities, electrocardiography) and special examination methods (ultrasonography using FAST method, computer tomography, nuclear-magnetic tomography, pathomorphological study of the damaged cells), invasive diagnostic procedures (thoracentesis, abdominal paracentesis (diagnostic peritoneal lavage, videolaryngoscopy), and statistic examination methods.

The scope of medical aid for the traumatized at the pre-hospital stage depended upon the subjective assessment of the patients' general condition by the emergency team. Polytraumatized patients were diagnosed and treated at hospital according to the common and local protocols, which included the collection and analysis of the complaints, medical history and features of the traumatizing factor $[1,2,10]$.

\section{RESULTS}

Main principles of rendering the aid to the polytraumatized overweight patients included the pathophysiological and topographic features of the group.

During the diagnostics of the thoracal trauma, apart from the traditional $\mathrm{x}$-radiography which was not always quite informative, for the verification of diagnosis in the patients against the background of II-III grade obesity, the thoracocentesis was applied. Thus, in major group 33 patients (97.1\%) were punctured, while in the approbation - 29 (96.7\%) which provided for the accurate diagnostics of the pleural and pulmonary complications resulting from the blunt chest injury ( $\left(p>0.05 ; \chi^{2}=0.01\right)$. General typical characteristics of the blunt chest injury in case of II-III grade obesity are shown in Table II.
Following the stated algorithm of the diagnostics of the blunt chest injury allowed detecting the contusion-laceration of lungs in $100 \%((p>0,001)$ and, accordingly, conducting the timely drainage of the pleural cavities.

With regard to the treatment characteristics of the severe thoracic trauma in the patients with II-III grade obesity, and for the purpose of treatment and prevention of the early and late infectious complications through the therapeutic bronchoscopy procedures the tracheostomy is recommended for such patients. Thus, in major clinical group, tracheostomy was performed in $25(73.5 \%)$, approbation group - in $30(100 \%)$ cases which fully confirmed the necessity of this procedure for the overweight patients $(\mathrm{p} \leq 0.05 ; \chi 2=9.24)$.

Respiratorydistresssyndrome(RDS) developedin 17(50.0\%) patients of the major clinical group and in $23(57.7 \%)$ - of the approbation clinical group $\left(\mathrm{p} \leq 0.05 ; \chi^{2}=4.84\right)$.

All $64(100 \%)$ patients were diagnosed the blunt intra-abdominal injury. For the purpose of diagnostics of the intra-abdominal injuries, apart from ultrasonic diagnosis (using FAST) method, the invasive diagnostic procedures, in particular, abdominal paracentesis (diagnostic peritoneal lavage, videolaryngoscopy and diagnostic videolaryngoscopy were applied to the patients with II-III grades obesity.

As Table III shows it, the invasive methods of the abdominal injuries diagnostics in case of polytrauma in the overweight patients should be predominant among the existing approaches which is confirmed by the calculation results in the approbation group. Positive result of the stated methods was observed in $25(70.6 \%)$ patients in the major group and in 27 (90.0\%) of the approbation group which became a defining criterion in the indications for the urgent surgical interference $\left(\mathrm{p}>0.05 ; \chi^{2}=2.84\right)$.

It should be stated that the trauma of the internals was predominantly composed of the injuries of parenchy- 
mal organs, in particular, the spleen lacerations were observed in $14(41.2 \%)$ of the major and $15(50.0 \%)$ of the approbation $\left(\mathrm{p}>0.05 ; \chi^{2}=0.50\right)$ group, and the liver lacerations in $21(61.8 \%)$ vs2 $4(80.0 \%)$ correspondingly $\left(\mathrm{p}>0.05 ; \chi^{2}=2.54\right)$.

The programed or emergency relaparotomy practically in each second patient is the characteristic feature of the course of traumatic disease in patients with II-III grades obesity. Thus, the relaparotomy ratio in the major group was $16(47.1 \%)$ cases and in the approbation - $19(63.3 \%)$, which confirmed the correctness of the chosen treatment method ( $\left.p>0.05 ; \chi^{2}=1.70\right)$.

One of the indications for the urgent relaparotomy in case of II-III grade obesity is the development of abdominal compartment syndrome (ACS) diagnosed in $12(35.3 \%)$ of the major group and in $17(57.7 \%)$ of the approbation group. The development of ACS in case of obesity caused searching for the optimal treatment method which, for the patients of the present group, was the application of the suspended ileostomy elaborated as based on the patients of the major group, and the grounding of its application was proved on the patients of the approbation group $\left(\mathrm{p}>0.05 ; \chi^{2}=2.94\right)$.

The next step of the research was the separation of the common skeleton injuries in case of II-III grade obesity. The fractures were typically located in the pelvic bones - $28(82.3 \%)$ major and 28 (93.3\%) approbation group $\left.\mathrm{p}>0.05 ; \chi^{2}=1.76\right)$, and hip fractures $-14(41.1 \%)$ vs $8(26.7 \%)$ correspondingly $\left(\mathrm{p}>0.05 ; \chi^{2}=1.49\right)$.

Fractures of extremities of the other location were more rare, in particular, $12(35.3 \%)$ in the major and $12(40.0$ $\%)$ in the approbation group ( $\left.\mathrm{p}>0.05 ; \chi^{2}=1.50\right)$.

The blunt craniocerebral injury was predominantly composed of the light and medium cerebral contusions without the surgical treatment necessity. Thus, in the major group the cerebral contusion was diagnosed in $24(70.9 \%)$, and in the approbation in $20(66.6 \%)$ cases $\left(\mathrm{p}>0.05 ; \chi^{2}=0.11\right)$.

Median hospital treatment duration in case of polytrauma against the background of II-III grade obesity in the major group was $31.0 \pm 1.6$, and in the approbation $-30.7 \pm 1.5$ beddays $(\mathrm{p}>0.05)$. Mortality in the major group was $5.9 \%(\mathrm{n}-2)$ in the approbation $-3.3 \%(n-1) ; p>0.05 ; \chi^{2}=0.23$.

\section{DISCUSSION}

The obtained study results confirmed the credible difference of the traumatic disease progress in the patients with the normal weight and overweight patients which was the basis of our differential complex treatment program. Noteworthy that our results were correlated with the data of the other authors $[8,9]$ who stated that the diagnostic accuracy of some visualization examination methods of the patients with the polytrauma is reduced in direct ratio to the grade of obesity. The higher obesity grade the smaller percent of the instrumental diagnostic approaches reliability in such patients. This causes the necessity of more frequent implementation of the invasive methods, which, on the one hand improved the injuries verification, and on the other - provoked the risks of complications connected both with their implementation and intervention into the body cavities $[1,6]$.

The treatment tactics also had certain characteristics connected with the obesity. The development of RDS syndrome is a typical stage of the traumatic disease during the blunt thoracic trauma in case of obesity, in the treatment of which, apart from the drug treatment, the therapeutic bronchoscopy is predominant, which caused the necessity of tracheotomy on 2-3 day from the moment of the artificial pulmonary ventilation.

The programmed and urgent relaparotomy, as a method of the stage treatment of the traumatic disease in the present group of patients, is the integral component of the blunt abdominal injury in case of obesity. The said approaches proved their credibility in the treatment of ACS through the application of the suspended ileostomy.

\section{CONCLUSIONS}

The study results proved that our complex program of diagnostics and treatment of the polytraumatized patients shall be basic for the patients with II-III grade obesity.

\section{REFERENCES}

1. Chen A, Jeffcoach D, Stivers J et al. The impact of obesity on severity of solid organ injury in the adult population at a Level I trauma center. Trauma Surgery and Acute Open Care. 2019; 4(1): 1-4.

2. Marina I, Grintescu I, Cucereanu V. et al. The influence of parenteral glutamine supplementation on glucose homeostasis in critically ill polytrauma patients - A randomized-controlled clinical study. J.Clinical Nutricion. 2015:34(3):377-382.

3. Neville A, Brown CV, Weng J. et al. Obesity is an independent risk factor for mortality in severely injured blunt trauma patients. Arch Surg. 2004;139:983-987.

4. Haines K, Clayton J, Agarwal R. et al. Effects of Obesity on Penetrating Trauma. Journal of American College of Surgeons. 2018;227(4): 62-65.

5. Chuang J.F., H.T. Liu., Ch. Sh. Rau et al. Obese patients who fall have less injury severity but a longer hospital stay than normal-weight patients. World Journal of Emergency Surgery. 2016;11:11-14.

6. Bokhari F, Chih Yuan Fu, Francesco Bajani et al. Morbid Obesity Is Protective in Blunt abdominal trauma. Journal of American College of Surgeons. 2018; 227(4); 63-66.

7. Licht H, Murray M, Vassaur J, Jupiter DC. et al. The Relationship of Obesity to Increasing Health-Care Burden in the Setting of Orthopaedic Polytrauma. J Bone Joint Surg Am. 2015;18;73-81.

8. Gray S, Dieudonne B. Optimizing Care for Trauma Patients with Obesity. Cureus. 2018;10(7):3021-27.

9. Wagner E.R., Kamath A.F., Fruth K.M. et al. Effect of Body Mass Index on Complications and Reoperations After Total Hip Arthroplasty. Journal of Bone and Joint Surgery. 2016; 98(3):169-179.

10. Khimich S. Crush-Syndrome. Compartment-Syndrome. Polytrauma. In: Khimich S.D., Zheliba M.D., Herych I.D. eds. General Surgery, 3-rd Edition. Kyiv: 2019, p. 268-273.

This article is part of the topic of research work of the General Surgery Department of National Pirogov Memorial Medical University "Prevention and complex treatment of postoperative complications and purulent-inflammatory diseases" 
ORCID and contributionship:

Orest M. Chemerys - 0000-0001-8550-6980 A,B,D

Olena V. Katelian - 0000-0003-2343-9983 D,C

Sergii D. Khimich - 0000-0002-8643-2140 E,F

Ihor V. Stoianovskyi - 0000-0003-3336-1016 ${ }^{C, D}$

\section{Conflict of interest:}

The Authors declare no conflict of interest.

\section{CORRESPONDING AUTHOR}

\section{Orest M. Chemerys}

Lviv National Medical University, Lviv Ukraine

16 Sakharova str., Lviv, 79000

tel: +38097953 4443

e-mail: orestchemerys@gmail.com

Received: 17.01 .2020

Accepted: 05.03.2020

A - Work concept and design, B - Data collection and analysis, C - Responsibility for statistical analysis,

$\mathbf{D}$-Writing the article, $\mathbf{E}$-Critical review, $\mathbf{F}$ - Final approval of the article 